\title{
Evaluation of the Results of Radical Management of a Cohort of 107 Patients with Hepatocellular Carcinoma in Colombia
}

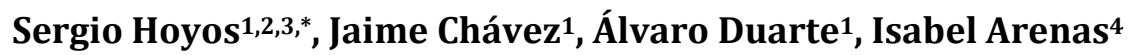 \\ ${ }^{1}$ Hepatobiliary and Liver Transplant Program, Hospital Pablo Tobon Uribe-Universidad de Antioquia, Medellín, \\ Colombia \\ ${ }^{2}$ Gastrohepatology Group, Universidad de Antioquía, Medellín, Colombia \\ ${ }^{3}$ Epidemiology, Universidad CES, Medellín, Colombia \\ ${ }^{4}$ Universidad San Martin, Medellín, Colombia \\ Email: *sergiohoyosd@yahoo.es
}

Received 10 October 2015; accepted 30 November 2015; published 3 December 2015

Copyright (C) 2015 by authors and Scientific Research Publishing Inc.

This work is licensed under the Creative Commons Attribution International License (CC BY).

http://creativecommons.org/licenses/by/4.0/

(c) (i) Open Access

\begin{abstract}
Introduction: Hepatocellular carcinoma (HCC) is the most common primary tumor of the liver and usually appears as part of liver cirrhosis (LC). Its management in the presence of LC is ideally with orthotopic liver transplantation. Surgical resection is indicated only in the presence of a tumor in a patient with a very good liver function and who for medical reasons cannot be carried to transplantation. Materials and Methods: A descriptive study of a prospective and consecutive series of patients undergoing surgery (resection or liver transplantation) for HCC in a hospital in the city of Medellin was performed, from June 2004 to January 2015. A multivariate analysis was carried out of factors associated with survival during the follow-up. Results: 116 surgical interventions for the management of HCC between June 2004 and January 2015 were performed. The analysis included 107 patients, of which $73 \%$ were men. The median age of all patients was 60 years. The factors that showed better survival were: patients undergoing transplantation, the presence of cirrhosis, tumor less than $5 \mathrm{~cm}$ in diameter, a unique and well-differentiated tumor; however, none of these factors achieved statistical significance. Conclusion: Both resection and liver transplantation, when well indicated achieve good 5-years of survival in patients with HCC.
\end{abstract}

\section{Keywords}

Liver Cancer, Cirrhosis, Liver Transplant

\footnotetext{
${ }^{*}$ Corresponding author.
}

How to cite this paper: Hoyos, S., Chávez, J., Duarte, Á. and Arenas, I. (2015) Evaluation of the Results of Radical Management of a Cohort of 107 Patients with Hepatocellular Carcinoma in Colombia. Journal of Cancer Therapy, 6, 1137-1144. 


\section{Introduction}

Hepatocellular carcinoma (HCC) is the most common primary tumor of the liver and usually appears as part of liver cirrhosis (LC) [1]. The frequency of HCC varies widely depending on the geographical location, and the distribution is often different between different ethnic groups and gender. It is a problem of less developed regions where more than $80 \%$ of the cases occur. It is the fifth most common cancer in men and the ninth in women [2]. It is the second leading cause of cancer death worldwide, responsible for approximately 746,000 deaths in 2012; the prognosis is very poor and this is reflected in the overall incidence rate of mortality of 0.95 [2] [3].

In Colombia, HCC occupies the fifteenth place in incidence and the seventh place in mortality according to Globocan data, but with limitations due to the bad records that exist in the country. In men, it ranks twelfth in incidence and is the fifth leading cause of mortality [4].

Latino-American data are scarce about HCC, but it is estimated that the incidence is 5 cases per 100,000 individuals [5].

Often, the diagnosis of HCC is delayed due to the large functional reserve of the liver and the absence of specific signs and symptoms that make suspect the disease [6]-[8]. It is important to note that this tumor does not require biopsy for diagnosis in patients with cirrhosis and with typical images in CT scan or MRI images [9]. The development of HCC in cirrhotic patients is variable according to the ethology of HCC being more prevalent in patients infected with hepatitis B virus and hepatitis $C$ virus than patients with autoimmune or cholestasis cirrhosis. The incidence in this case varies between $3 \%$ and $4 \%$ per year [10].

In the presence of LC and in early stage HCC, the best management is orthotopic liver transplantation (OLT), as long as the patient is fit to tolerate the procedure [8]. The most frequently used staging criteria are the Barcelona Clinic Liver Cancer, which although it is not approved by all the world groups, it has been the basis of the guidelines of both the American Association for the Study of Liver Disease and the European Association for Study of the Liver. The tumors considered for OLT are: a single lesion of $5 \mathrm{~cm}$ in diameter or less, or 3 or fewer lesions each one of $3 \mathrm{~cm}$ or less (the Milan criteria) [8] [10]. When the patient does not meet these criteria, it is not an early tumor and then is not a candidate for OLT, and other strategies must be considered. One of the options that can be considered for this management is surgical resection, but it requires a very good liver function in the patient. When there is no LC, hepatic resection is the preferred management and can be more aggressive in view of the good liver function; the problem is that most of these patients have large tumors due to the absence of regular surveillance because they are not cirrhotics.

The present study aims to describe the results in terms of survival with surgical management of patients with HCC, regardless of whether they have undergone surgical resection or liver transplantation. The aim is also to look for the relationship between different demographic and pathological variables with respect to this survival.

All patients were treated at a hospital in Medellin (Colombia) between June 2004 and January 2015.

Methods: A retrospective study of a consecutive series of patients collected prospectively was performed. Secondary sources of information were used (prospective database of the unit and medical records when data were missing). All patients undergoing liver transplantation or resection, whose pathology corroborated the diagnosis of HCC were included.

Patients with previous HCC diagnosed by images, but with no tumor in the pathology analysis were excluded. All patients were followed in the Hepatobiliary and Liver transplant unit of the same hospital.

For the analysis, the following variables were recorded: demographics (age, sex), clinical (etiology of cirrhosis, previous complications), and histopathology (number and size of tumors, vascular invasion, and cell differentiation). All of these were the independent variables; the dependent variable was death.

\section{Statistical Analysis}

For the univariate statistical analysis, frequency measures of central tendency are described. In addition, the survival analysis with Kaplan Meier was calculated. In bivariate analysis Chi square for categorical variables and U Mann Whitney for continuous variables with a significance of $p<0.05$ were used; for survival, the analysis log rank test was used with a significance of $p<0.05$.

In multivariate analysis a Cox regression (using the Hosmer-Leme show test (HL) with $p<0.25$ ) was performed, and the crude hazard ratio was calculated and then adjusted to determine the change in the measure of association. The value of significance accepted was $p<0.05$. The statistical analysis was performed using the SPSS version 21 (Statistical Package for the Social Sciences Inc.; Chicago, Illinois, USA). 


\section{Results}

116 surgical interventions were performed for the management of HCC between June 2004 and January 2015 at the Pablo Tobon Uribe Hospital (HPTU) in Medellin; of these, nine transplanted patients were excluded because it was not possible to corroborate tumor in the explants, all of them with decompensated cirrhosis that was the indication of liver transplant.

Of the 107 patients included in the final analysis, 73\% were men. The median age of all patients was 60 years (Kolmogorov Smirnov $p<0.05$; interquartile range 54 - 65 years).

$70 \%$ of the patients had LC, the most frequent etiology was alcohol abuse, Hepatitis virus B and virus $\mathrm{C}$ infection (15\%, $13 \%$ and $12 \%$ respectively).

The procedures performed were 67 OLT and 40 liver resections. As expected, resected and transplanted patients are not comparable in some specific aspects that make them tributary of one or the other procedure, such as having cirrhosis and tumor size, since OLT is carried out in the presence of HCC almost exclusively if there is hepatic cirrhosis and the international guidelines are very conservative in terms of tumor size and number to recommend liver transplantation. Advanced age is another important factor to consider, since it is by itself one of the counter-indications for OLT in many groups in the world. Other features of the two groups are presented in Table 1.

General pathological features: $56 \%$ of the patients had a single tumor, $44 \%$ had multiple tumors and of these, $22.4 \%$ had satellite nodules. $70 \%$ had tumors of $5 \mathrm{~cm}$ or less in diameter. Transplanted patients had significantly more satellites than resected patients $(p=0.03)$ and their tumors were smaller $(p=0.000)$. Microscopic vascular involvement was present in $22.4 \%$ of the cases in general, and no differences between the two groups (OLT or resection) were noted. HCCs were well differentiated according to the Edmonson Steiner classification in 35\% of transplanted livers and $57.5 \%$ of resected livers $(p=0.03)$.

Survival: The average survival for the entire cohort was 76.7 months (95\% Confidential Interval 64.8 - 88.6), the survival of all patients was $37.6 \%$ at 107 months (Figure 1), survival after one year was $86.7 \%$ and after 5 years it was $62 \%$.

In the bivariate analysis, an improved survival of patients younger than 60 years with a single, smaller tumor was observed in those who underwent liver transplantation (and therefore were cirrhotic), but none of these differences were statistically significant. Neither the microscopic vascular compromise, nor the degree of cell differentiation showed differences in survival (Table 2).

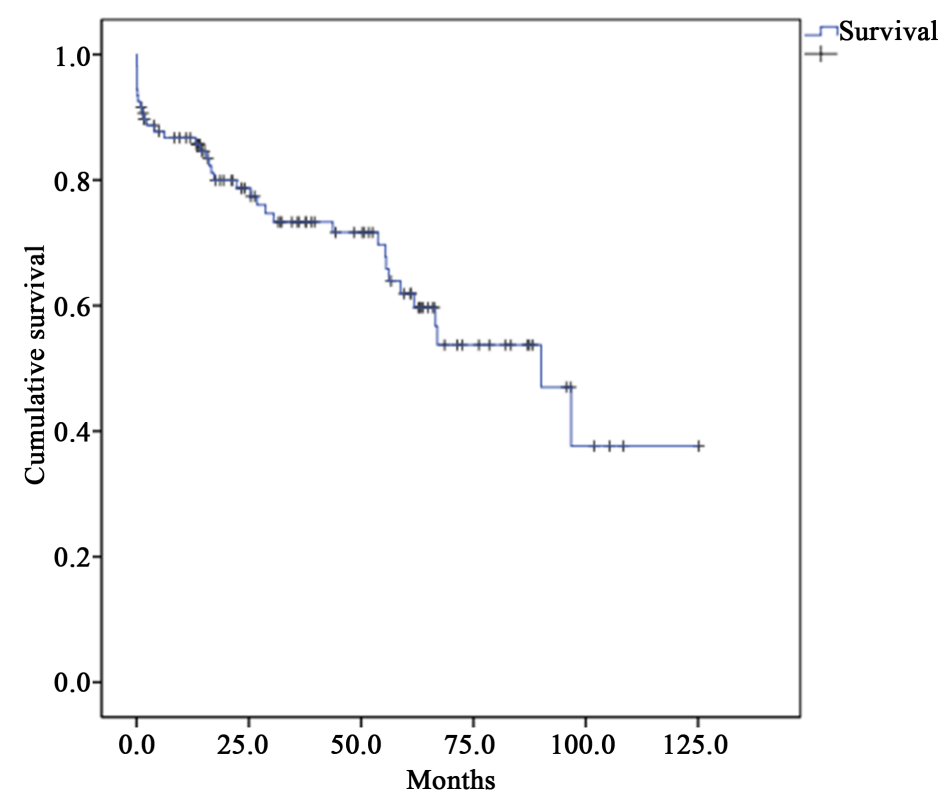

Figure 1. Overall survival in patients undergoing resection or transplantation for HCC. HPTU, Medellin, 2004-2015. 
Table 1. Demographic, clinical, and pathology of patients undergoing resection or transplantation for HCC. HPTU, Medellin Data, 2004-2015.

\begin{tabular}{cccc}
\hline Variable & OLT & Resection & $p$ \\
Age & Me 58 years (Rq 52 - 62) & Me 66 years (Rq 60 - 75) & 0.0001 \\
$<60$ years & $68.7 \%$ & $27.5 \%$ & 0.1 \\
Man & $79 \%$ & $63 \%$ & 0.000 \\
Hepatic cirrhosis & $100 \%$ & $30 \%$ & 0.216 \\
Tumor (single) & $51 \%$ & $65 \%$ & 0.000 \\
Tumor (size) & Me 3cm & Me $7 \mathrm{~cm}$ & 0.000 \\
Tumor (<5 cm) & $91 \%$ & $35 \%$ & 0.685 \\
No vascular invasion & $64 \%$ & $70 \%$ & 0.03 \\
Satellite positive & $85 \%$ & $65 \%$ & 0.03 \\
Well differentiated & $35 \%$ & $57.5 \%$ &
\end{tabular}

Me: median; Rq: interquartile range.

Table 2. Relationship of the possible factors associated with survival of patients undergoing resection or transplantation for HCC. HPTU, Medellin, 2004-2015.

\begin{tabular}{|c|c|c|c|}
\hline Variable & Survival (months) & $\mathrm{IC}_{95 \%}$ & $p$ (lon-rank) \\
\hline $\begin{array}{l}\text { Age } \leq 60 \text { yrs } \\
\text { Age }>60 \text { yrs }\end{array}$ & $\begin{array}{l}80 \\
65\end{array}$ & $\begin{array}{l}64-97 \\
51-78\end{array}$ & 0.408 \\
\hline $\begin{array}{l}\text { Woman } \\
\text { Man }\end{array}$ & $\begin{array}{l}85 \\
65\end{array}$ & $\begin{array}{l}64-105 \\
55-75\end{array}$ & 0.359 \\
\hline $\begin{array}{c}\text { Resection } \\
\text { Liver transplant }\end{array}$ & $\begin{array}{l}63 \\
74\end{array}$ & $\begin{array}{l}44-81 \\
63-86\end{array}$ & 0.174 \\
\hline $\begin{array}{c}\text { Hepatic cirrhosis } \\
\text { No Hepatic cirrhosis }\end{array}$ & $\begin{array}{l}72.3 \\
65\end{array}$ & $\begin{array}{l}62-82 \\
41-88\end{array}$ & 0.181 \\
\hline $\begin{array}{c}\text { Tumor size } 3 \mathrm{~cm} \text { o less } \\
\text { Tumor size more than } 3 \mathrm{~cm}\end{array}$ & $\begin{array}{l}81 \\
67\end{array}$ & $\begin{array}{c}63-100 \\
56-79\end{array}$ & 0.754 \\
\hline $\begin{array}{l}\text { Tumor size } 5 \mathrm{~cm} \text { o less } \\
\text { Tumor size more than } 5 \mathrm{~cm}\end{array}$ & $\begin{array}{l}82 \\
53\end{array}$ & $\begin{array}{l}68-96 \\
40-65\end{array}$ & 0.131 \\
\hline $\begin{array}{l}\text { No vascular invasion } \\
\text { Yes vascular invasion }\end{array}$ & $\begin{array}{l}69 \\
68\end{array}$ & $\begin{array}{l}59-78 \\
48-89\end{array}$ & 0.639 \\
\hline $\begin{array}{l}\text { Satellite positive } \\
\text { Satellite negative }\end{array}$ & $\begin{array}{l}81 \\
54\end{array}$ & $\begin{array}{l}67-94 \\
33-74\end{array}$ & 0.084 \\
\hline $\begin{array}{c}\text { Well differentiated } \\
\text { Not Well differentiated }\end{array}$ & $\begin{array}{l}81 \\
59\end{array}$ & $\begin{array}{l}66-95 \\
45-73\end{array}$ & 0.258 \\
\hline $\begin{array}{l}\text { Single tumor } \\
\text { No single tumor }\end{array}$ & $\begin{array}{l}84 \\
61\end{array}$ & $\begin{array}{c}68-100 \\
47-74\end{array}$ & 0.131 \\
\hline $\begin{array}{c}\text { Survival ONLY resection } \\
\text { Cirrhosis } \\
\text { No cirrhosis }\end{array}$ & $\begin{array}{l}53 \\
65\end{array}$ & $\begin{array}{l}38-67 \\
41-88\end{array}$ & 0.79 \\
\hline
\end{tabular}

The survival rate at one and five years was $83.5 \%$ and $71.7 \%$ in transplanted patients, and $92 \%$ and $36 \%$ in resected patients $(p=0.174$ ) (Figure 2). For cirrhotic patients the one and five years survival was $89.3 \%$ and $66.9 \%$ versus $89 \%$ and $35 \%$ in non cirrhotic patients $(p=0.181$ ) (Figure 3 ). When satellite was found, the one and five years survival was $83.1 \%$ and $51 \%$ versus $87.8 \%$ and $65.4 \%$ if no satellite was found $(p=0.08)$ (Figure 4). 


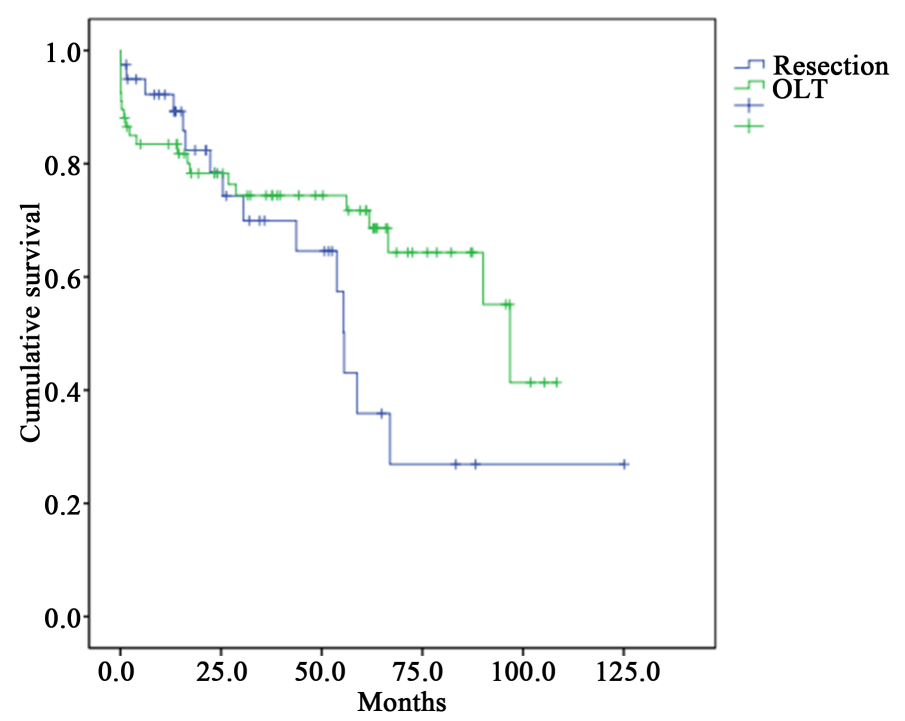

Figure 2. Survival in patients undergoing radical treatment for HCC by type of intervention (transplantation or resection). HPTU, Medellin, 2004-2015.

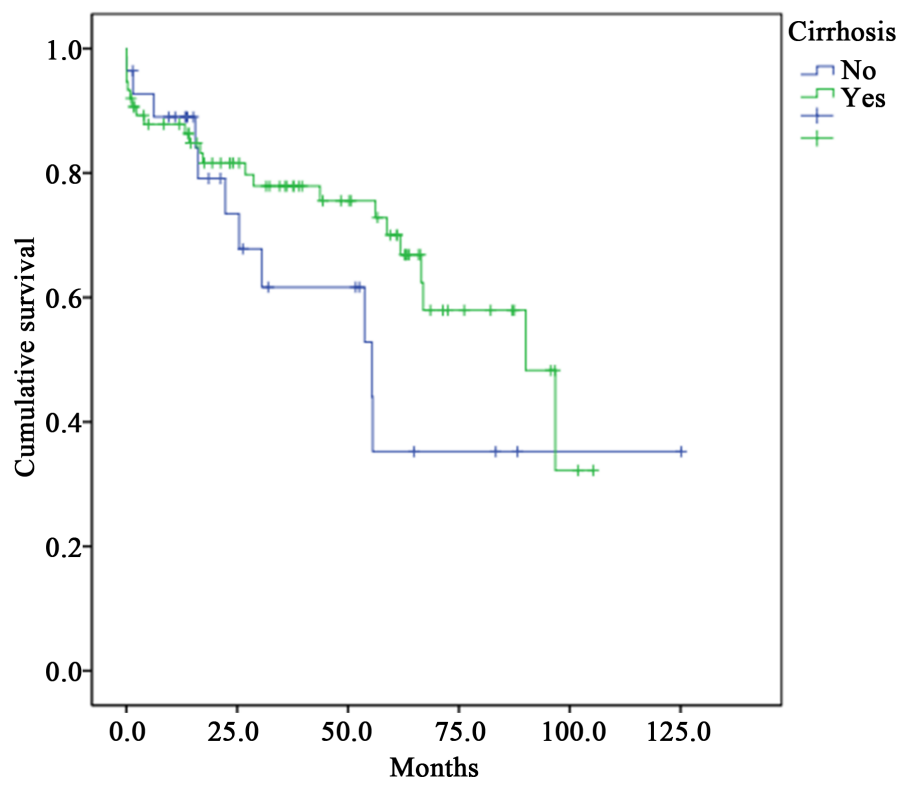

Figure 3. Survival in patients undergoing resection or transplantation for HCC, according to a history of liver cirrhosis. HPTU, Medellin, 2004-2015.

Concerning the characteristics of the tumor, its size was not related to the existence of vascular involvement in the pathology $(p=0.412)$, but it was related to the presence of satellites $(p=0.004)$ and with poorly differentiated tumors $(p=0.006)$.

There were significantly more large tumors in resected vs transplanted patients $(p=0.000)$.

No relationship between the degree of differentiation and vascular involvement was observed $(p=0.06)$.

When analyzing survival only in patients who were resected, it was observed that they presented a better survival rate when they were not cirrhotics, but without statistical significance $(p=0.79)$ (Figure 5).

Subsequently a Cox regression was performed to establish a multivariate analysis of the variables that have more weight in relation to the long-term survival in this cohort of patients. Crude hazard ratio was calculated and then adjusted to determine the change in the measure of association using the bivariate analysis, for those that reached statistical significance (Hosmer Lemeshow $<0.25$ ). 


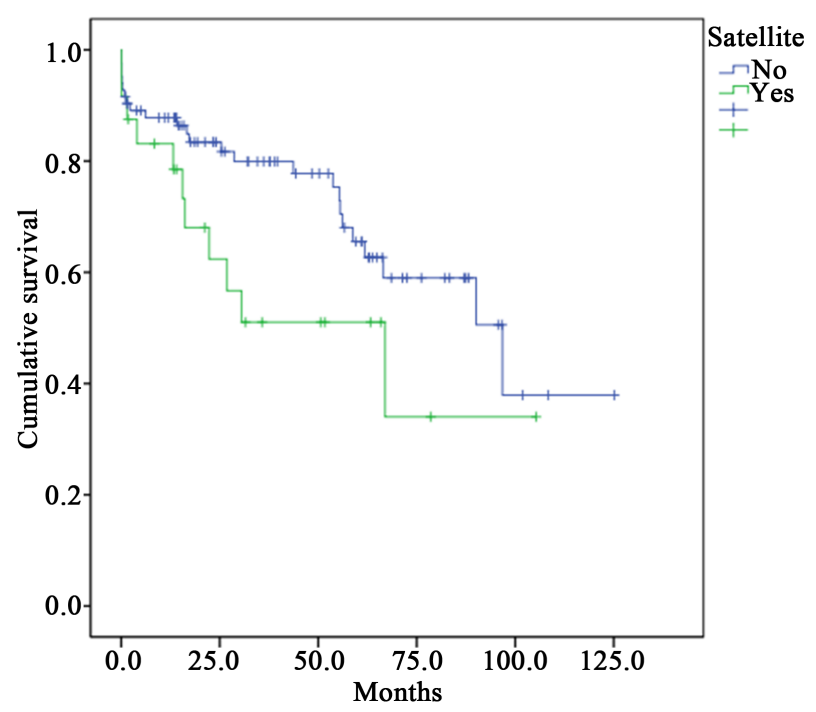

Figure 4. Survival in patients undergoing resection or transplantation for HCC, according to presence of satellites. HPTU, Medellin, 2004-2015.

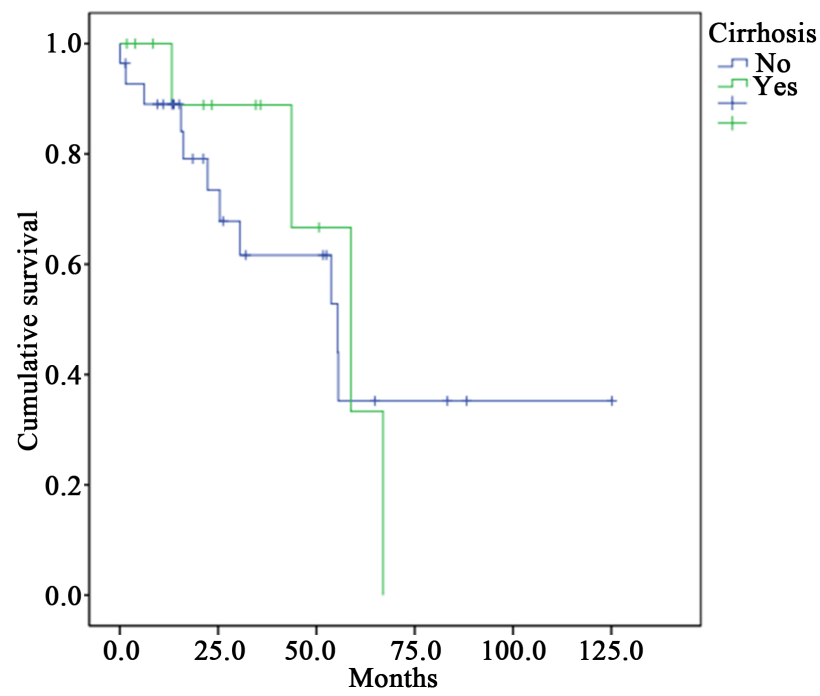

Figure 5. Survival in patients undergoing only resection for HCC (transplants are excluded), according to the presence of cirrhosis. HPTU, Medellin, 2004-2015.

This analysis showed that the tumor size, the presence of several tumors and of satellites were the most important risk factors leading to a minor survival rate in both crude and adjusted analyzes; however none of these risk factors reached statistical significance (Table 3).

\section{Discussion}

One important aspect of this study is that it presents epidemiological and demographic data from HCC as well as survival in a Latin-American population. The distribution of HCC by sex in Colombia is much higher in men than in women as has been previously reported [11].

It is clear that radical management with liver transplantation is the better option, with 5 years survival of over $70 \%$ of the patients in different regions around the world. This strategy not only controls the tumor but also the underlying liver cirrhosis, so the benefits are clear. Yet, the shortage of organs in many countries and the fact that not every patient can achieve the minimum criteria for admission on a transplant list shows that hepatic resection is a good alternative for treatment. 
Table 3. Factors related to survival in patients undergoing resection or transplantation for HCC. HPTU, Medellin, 20042015.

\begin{tabular}{|c|c|c|c|c|}
\hline Variable & HR crude & $\mathrm{IC}_{95 \%}$ & HR adjusted & $\mathrm{IC}_{95 \%}$ \\
\hline Resection & 1.58 & $0.809-3.122$ & 0.862 & $0.23-3.23$ \\
\hline Liver transplant & 1.0 & & 1.0 & \\
\hline Cirrhosis yes & 0.613 & $0.297-1.265$ & 0.623 & $0.188-2.061$ \\
\hline Cirrhosis no & 1.0 & & 1.0 & \\
\hline Tumor size $>5 \mathrm{~cm}$ & 1.699 & $0.846-3.41$ & 1.468 & $0.543-3.969$ \\
\hline Tumor size $<5 \mathrm{~cm}$ & 1.0 & & 1.0 & \\
\hline Satellite positive & 1.855 & $0.91-3.782$ & 1.542 & $0.613-3.876$ \\
\hline Satellite negative & 1.0 & & 1.0 & \\
\hline Not Well differentiated & 0.679 & $0.346-1.334$ & 0.764 & $0.359-1.625$ \\
\hline Well differentiated & 1.0 & & 1.0 & \\
\hline No single tumor & 1.65 & $0.854-3.186$ & 1.671 & $0.728-3.834$ \\
\hline Single tumor & 1.0 & & 1.0 & \\
\hline
\end{tabular}

Few regions in Latin America show long-term results with radical management of HCC [11]-[13].

The most important finding of this study was the acceptable 5-year survival achieved independently of the radical management, although it is clear that transplanted patients present some favorable characteristics that allow them to present a better survival over resected patients, but in this group, survival is also acceptable given that none of them were candidates for liver transplantation.

A Peruvian report [12] with 190 liver resections in a group of patients, $49 \%$ of whom with hepatitis B virus or hepatitis $C$ virus infection and with 41 year-olds on average, recorded a significant number of resections in patients with multiple tumors (30\%), but with a post-operative mortality of $13.7 \%$ and a median survival of 22.8 months; the overall survival at 1 and 5 years was $66.49 \%$ and $26.65 \%$ respectively, lower than those reported in this series.

Another study from Chile reported 19 operations in 29 patients with HCC, with a mean age of 57.3 years, but only 6 patients achieved resection because advanced disease was revealed in the operating room; the overall survival of these resected patients was very poor, only 8.5 months [13].

Finally, a recent multicenter study in North America, Europe and Asia, reported a series of 334 patients treated for HCC, including 319 (95.5\%) who were treated with liver resection and $0.9 \%$ with OLT, the median age was 58 years, $77 \%$ were men and $51 \%$ had been infected with hepatitis B or hepatitis C virus. $81 \%$ had single tumors, $70 \%$ had tumors of more than $5 \mathrm{~cm}$, and the survival at 1 and 5 years was $85 \%$ and $52 \%$, similar to that reported in our study.

Predictors of recurrence reported in this multicenter study were similar to ours, namely: poor cellular differentiation of the tumor, and the presence of multiple tumors or satellites. The microscopic vascular invasion did not affect survival, as in our experiments [14].

The limitations of the present study include the small number of patients and its retrospective nature, but with very good information about patient demographics, surgical and pathology reports. Full post-operative control in the same location, allowed us to analyze adequate data for this study.

\section{Conclusion}

In conclusion, we can conclude that the survival of patients with HCC is compromised with liver resection, but given that there is no option for OLT in these patients, liver resection is a very good option with adequate five year survival rates. 


\section{Funding}

Sustainability Project Vicerrectoría Research, Universidad de Antioquía.

\section{References}

[1] Parikh, S. and Hyman, D. (2007) Hepatocellular Cancer: A Guide for the Internist. The American Journal of Medicine, 120, 194-202. http://dx.doi.org/10.1016/j.amjmed.2006.11.020

[2] GLOBOCAB 2012: Estimated Cáncer Incidence, Mortality and Prevalence Worldwide in 2012. http://globocan.iarc.fr/Pages/fact_sheets_cancer.aspx

[3] Parkin, D., Bray, F., Ferlay, J. and Pisani, P. (2005) Global Cancer Statistics, 2002. CA: A Cancer Journal for Clinicians, 55, 74-108. http://dx.doi.org/10.3322/canjclin.55.2.74

[4] GLOBOCAB 2012: Estimated Cáncer Incidence, Mortality and Prevalence. http://globocan.iarc.fr/Pages/fact_sheets_population.aspx

[5] Boyle, P. and Levin, B., Eds. (2008) World Cancer Report. IARC Press, Lyon, 350-357.

[6] El-Serag, H. and Rudolph, K. (2007) Hepatocellular Carcinoma: Epidemiology and Molecular Carcinogenesis. Gastroenterology, 132, 2557-2576. http://dx.doi.org/10.1053/j.gastro.2007.04.061

[7] Kew, M., Dos Santos, H. and Sherlock, S. (1971) Diagnosis of Primary Cancer of the Liver. British Medical Journal, 4, 408-411. http://dx.doi.org/10.1136/bmj.4.5784.408

[8] Bruix, J. and Sherman, M. (2005) Management of Hepatocellular Carcinoma. Hepatology, 42, 1208-1236. http://dx.doi.org/10.1002/hep.20933

[9] Llovet, J. and Beaugrand, M. (2003) Hepatocellular Carcinoma: Present Status and Future Prospects. Journal of Hepatology, 38, S136-S149. http://dx.doi.org/10.1016/S0168-8278(02)00432-4

[10] Bruix, J., Sherman, M., Llovet, J., Beaugrand, M., Lencioni, R., Burroughs, A., et al. (2001) Clinical Management of Hepatocellular Carcinoma. Conclusions of the Barcelona 2000 EASL Conference. Journal of Hepatology, 35, 421-430. http://dx.doi.org/10.1016/S0168-8278(01)00130-1

[11] Hoyos, S., Escobar, J., Cardona, D., Guzmán, C., Mena, A., Osorio, G., et al. (2015) Factors Associated with Recurrence and Survival in Liver Transplant Patients with HCC-A Single Center Retrospective Study. Annals of Hepatology, 14, 58-63.

[12] Ruiz, E., Sanchez, J., Celis, J., Payet, E., Berrospi, F., Chavez, I., et al. (2007) Resultados a corto y largo plazo de la Resección Hepática por Hepatocarcinoma. Análisis de 232 Resecciones Consecutivas. Rev Gastroenterol Perú, 27, 223-235.

[13] Manterola, C., Muñoz, S., Araya, J.C., Calderón, C. and Barroso, M.S. (2000) Clinical Features of 29 Patients with Hepatocellular Carcinoma. Revista Médica de Chile, 128, 896-898.

[14] Arnaoutakis, D., Mavros, M., Shen, F., Alexandrescu, S., Firoozmand, A., Popescu, I., et al. (2014) Recurrence Patterns and Prognostic Factors in Patients with Hepatocellular Carcinoma in Noncirrhotic Liver: A Multi-Institutional Analysis. Annals of Surgical Oncology, 21, 147-154. http://dx.doi.org/10.1245/s10434-013-3211-3 